\title{
Digitalisation of continuous mine closure planning and management: an EIT RawMaterials initiative
}

\author{
T Kauppila Geological Survey of Finland, Finland \\ G Bellenfant French Geological Survey, France \\ L Solismaa Geological Survey of Finland, Finland \\ P Mittelstädt DMT GmbH \& Co. KG, Germany
}

\begin{abstract}
The current paradigm in mine closure is continuous, or progressive, mine closure, which is the industry standard for best closure outcomes. However, this is a complex management challenge because mine closure is a long, evolving process that can be hampered by changes in ownership and management. It involves external stakeholders, and the jointly planned post-closure land uses influence all closure plans and actions. Closure is also an official process with regulatory requirements and financial sureties.

Continuous closure also means continuous reduction of unknowns, risks and (financial) liabilities. Therefore, the constant accumulation of data and plans and the whole process need to be well documented. Such a complex undertaking needs tools that help in managing the process. We must take this beyond the conventional closure management plans (CMPs) written on paper to a digital system with enhanced capabilities for continuous closure management. At the same time, the authorities are going digital. Some European Union Member States and other countries around the world have set up, and are pursuing, e-government initiatives that are designed to help interaction with the authorities when applying for permits and licences, and submitting environmental impact assessments, etc. (EIAs) (e.g. the digital permit process management system in Germany called BergPass). This also concerns mining projects and the closure of mines. This development also means that CMPs need to comply with these systems, which also emphasises the need for digital closure management systems such as Closurematic: Management Tool for Continuous Mine Closure.

The Closurematic project (2018-2021), funded by the European Institute of Innovation and Technology on RawMaterials (EIT RM), is creating a new digital system for managing the mine closure process. Closurematic is a versatile digital tool to help mining companies and consultants plan, carry out, manage, monitor, communicate, and document mine closure at every step of a mining project. The tool adds value to a mining company's assets by creating continuity in the long-term management of closure-related data. Its main functions will include an easily adaptable master plan (using tailored templates), extended interactive guidance to help the user, links to the best international practices, a geographic information system (GIS) interface, a file repository to store documents relating to the closure, and interactive tables and charts to monitor the closure actions and associated costs.
\end{abstract}

Keywords: mine closure, software, digitalisation, continuous closure, progressive closure

\section{Introduction}

Mining is one of the rare industries that is based on projects with an inherently limited lifetime. It also involves long periods of post-operational management of reactive wastes generated during the production phase. This environmental legacy, which persists after mine closure, may be the most significant component of the environmental impacts of the whole operation. This is because improperly closed mines may affect the environment for decades or even centuries due to the slow spontaneous decomposition of the minerals contained in the mining wastes (tailings and waste rock) and other exposed surfaces. In addition, mine 
closure affects the regional economy and livelihoods and may cause demographic and social changes within the sphere of influence of the mine to be closed.

The eventual closing of a mine not only includes risks but also provides a wealth of opportunities if planned and executed prudently. Mines often operate in locations outside major population centres and can provide a basis for sustainable benefits, especially if economic diversification and the opportunities are taken into consideration early enough (see e.g. Queensland Government 2017).

Careful planning, a joint long-term vision, extensive collaboration and continuous work are required to minimise risks and negative impacts of mine closure while maximising long-term benefits from the opportunities provided by the mine site and its workforce. This has to be achieved in the context of the turbulent mining sector, with fluctuating commodity prices and frequent changes in personnel and ownership. At the same time, legal, administrative and financial liabilities must be managed. This means that mine closure is a long, complex management process that requires a wealth of expertise involving most departments of the mine and several external stakeholders.

The importance of closure for sustainable mining and the complexity of managing closure resulted in the European Institute of Innovation and Technology on RawMaterials (EIT RM) launching a project to develop digital tools for mine closure management (i.e. Closurematic). The EIT RM is a body of the European Union and the largest consortium in the raw materials sector worldwide. It includes more than 120 core and associate partners and more than 180 project partners from the industry, universities and research institutions from more than 20 European Union countries. They collaborate on finding new, innovative solutions to secure the supplies and improve the raw materials sector in Europe.

\section{Mine closure is a complex management challenge}

The complex mine closure process is typically managed with the help of closure management plans (CMPs). The difficulty of the mine closure process stems from several factors. The process is long, starting well before mining commences or even before the construction of the mine commences. In the early phase, the mine closure process involves interacting with the environmental impact assessment (EIA) process; identifying and engaging with stakeholders; setting initial closure objectives; taking part in the test processing of, and flow sheet development for, the ore; and giving inputs to the feasibility study. A conceptual CMP will evolve with the early phases of the mining project (exploration, pre-feasibility, feasibility, development phase). Then, the CMP will be adapted during the operation phase according to the monitoring results and modification of the mining processes (Table 1 ).

Table 1 Main phases of the mine closure process

\begin{tabular}{ll}
\hline Main phases of the mine closure process & Main inputs \\
\hline Pre-mining environment description & Exploration \\
Mine development selection & Pre-feasibility study \\
Operational control measures selection & Environmental and social impact assessment \\
Operational impact assessment & Feasibility study \\
Closure measures selection & Risk and impact assessment \\
Closure impact assessment & Stakeholder engagements \\
Monitoring and maintenance definition & \\
Costing and scheduling of plan & \\
Financial assurance provision & \\
Application & \\
Approval & \\
Implementation & \\
\hline
\end{tabular}


Thus, progressive closure will go on for years, with the aim of reducing the final closure liabilities as much as possible. The complexity also stems from the wide variety of mining processes. Table 2 presents an example of the structure of a CMP, which generally includes an introduction (project identification, main objectives), a description of the project (site description, results of the environment and social impact assessment, and the anticipated impacts), stakeholder engagement, the closure objectives (including completion criteria for all objectives), the closure plan for all parts of the project (a domain approach is considered as a good practice), the care and maintenance plan, and the closure management part (cost estimation, financial provisions, permitting, etc.)

Table 2 Example of closure management plan structure

\begin{tabular}{|c|c|c|c|}
\hline Chapter & Sub-chapter & Chapter & Sub-chapter \\
\hline \multirow{3}{*}{ Introduction } & Project identification & \multirow{9}{*}{ Closure plan } & Earth construction waste facilities \\
\hline & Purpose and scope & & Waste rock facilities \\
\hline & Endorsed checklist & & Tailings management facilities \\
\hline \multirow{6}{*}{$\begin{array}{l}\text { Project } \\
\text { information }\end{array}$} & Site description & & Process waste facilities \\
\hline & Project description & & Water management \\
\hline & Baseline (pre-mining) & & Water treatment \\
\hline & Present state (current & & Biodiversity management \\
\hline & impacts) & & Landscaping and landforms \\
\hline & Anticipated impacts & & \\
\hline \multirow{3}{*}{$\begin{array}{l}\text { Stakeholder } \\
\text { engagement }\end{array}$} & Planning phase engagement & & Revegetation and post-mining land \\
\hline & Continuous stakeholder & & use \\
\hline & Close planning process & & $\begin{array}{l}\text { Regional economic impacts } \\
\text { management }\end{array}$ \\
\hline \multirow{8}{*}{$\begin{array}{l}\text { Closure } \\
\text { objectives }\end{array}$} & Obligations and & \multirow{8}{*}{$\begin{array}{l}\text { Care and } \\
\text { management } \\
\text { plan }\end{array}$} & Monitoring \\
\hline & commitments & & Management structure and staffing \\
\hline & Defining post-closure land & & Closure planning process \\
\hline & uses & & Cost estimation \\
\hline & Identifying closure issues & & Financial provisions \\
\hline & Defining functional domains & & \\
\hline & Final closure objectives & & \\
\hline & Completion criteria & & \\
\hline \multirow{5}{*}{ Closure plan } & General approach & \multirow{5}{*}{$\begin{array}{l}\text { Closure } \\
\text { management }\end{array}$} & Permitting \\
\hline & Overview by domain & & Custodial transfer \\
\hline & Above-ground facilities & & Data management and \\
\hline & Open pit & & documentation \\
\hline & Underground mine & & Monitoring data \\
\hline
\end{tabular}

These elements may present a challenge at the final closure if the aims of the closure are not considered in the planning phase. This requires that the aims and progress of the closure are effectively communicated to all internal stakeholders and several external stakeholders. The financial department is one of these internal stakeholders as it wants to know how much funds are needed for mine closure at any given time and how much of the liabilities still remains to be covered. Furthermore, mine closure is not only an internal issue for the mining company. Several authorities also control the closure process, and the operator has to respect its 
engagement towards all stakeholders. Moreover, international standards for non-financial reporting, such as the Equator Principles (Equator Principles Association 2013), the International Finance Corporation's (IFC) Environmental and Social Performance Standards (IFC 2012) or the Global Reporting Initiative (GRI 2019) require recurrent disclosures. For example, the IFC in Performance Standard 1 (Assessment and Management of Environmental and Social Risks and Impacts) emphasises the need for an environmental and social assessment and management system (ESMS), including a CMP. In addition, a social licence to operate (Joyce \& Thomson 2000; Moffat \& Zhang 2014) - that is, the public acceptance for the project-should also be obtained. Given this context, mine closure has been rated among the top five operating risks in mining (World Risk Report 2018).

Current CMPs are still typically text documents, printed on paper and stored in the office of the person responsible for closure. CMPs are often primarily made for administrative purposes according to the requirements of the authorities or the regulations. This means that they are tedious to update and not designed as internal management documents, and that other methods must be used to track the progress of closure. For example, in Australia and Canada, a mine closure plan (MCP) has to be updated every three to five years (Kabir et al. 2015). There is clearly a need for a dedicated software for mine closure management that allows easy updates to an $\mathrm{MCP}$, real-time monitoring of progress and expenditure, and easy communication with the stakeholders. At the same time, the official documents should be produced with less effort than the current practice.

\section{The need for digital tools for closure planning}

Besides the management of the closure process, planning for closure can also benefit from digital tools. Digital tools that aid in drafting and storing plans exist and have been successfully used in mining projects (Mackenzie et al. 2008; Blackman et al. 2009) but may not include support for drafting the plans. At the same time, a wealth of information is available on both the mine closure process and the technologies that can be used in the actual closing of processes and facilities. However, this information is scattered, and it may be difficult to get a complete view of the subject matters involved. The International Council on Mining and Metals (ICMM) Integrated Mine Closure: Good Practice Guide (ICMM 2019) is one of the rare approaches that provide an extensive survey of all the elements that have to be included in the closure planning process. Indeed, many resources concentrate on single aspects of closure, such as stakeholder consultation, tailings management, water treatment, prevention of acid rock drainage (ARD) or environmental risk assessment. A digital tool that supports mine closure planning by providing guidance for also the individual closure tasks, rather than the administrative process only, can clearly be beneficial in the planning phase, even if it is the local conditions that dictate many of the solutions that are available.

Even with online guidance available, mine closure planning is never a single person or a single organisation effort. External consultants are typically employed to produce either the whole MCP or parts thereof or to undertake individual testing or design assignments for the plan. Therefore, a digital system must have the capacity to incorporate external contributions without compromising the integrity and security of data in use at the mine and at the corporate level.

The digital tools for closure planning can streamline the closure planning process and promote uniform high-quality plans by providing a consistent model for the management plans. Similarly, certain jurisdictions around the world have produced templates for the administrative MCPs not only to facilitate an efficient administrative process but also to ensure that all plans consider the essential components of mine closure. This approach can also be applied internally to the more complex and constantly evolving internal CMP, by introducing templates to the closure management software. However, since all mines are unique, the model must be flexible to accommodate the large variation within mining projects.

The rehabilitation strategy will need to define general rehabilitation goals, such as human and wildlife safety, the non-polluting state of soils or the ability of the land to sustain an agreed post-mining use. But more site-specific goals will be necessary, such as restoring stream patterns, achieving water quality that meets some specific beneficial use or achieving specific socio-economic outcomes. The definition of intended 
post-mining land uses (land use goals) will determine the rehabilitation goal. Based on this, it is possible to define the rehabilitation outcomes required and the associated actions. These actions will need performance indicators that can be measured reliably over time using accepted scientific techniques and standards to track the progress towards completion/relinquishment criteria. These indicators must be related to the environmental, social or economic contexts within a time category (development and mining, planning and earthworks, short- or long-term after cessation of operation) and designed in consultation with stakeholders. Allowance for tracking such indicators should be made in the digital tools for closure management. In addition, the residual risks must be managed according to the land use after rehabilitation. This can include long-term monitoring and residual risk payment to be made and tracked.

\section{$4 \quad$ Successful mine closure requires continuity}

Besides informed and uniform high-quality CMPs, digital tools for mine closure can support continuity in the long closure process. This stems from the ease of updating and maintaining the internal master plan of the mining project due to its digital nature. Digital tools also provide for tracking these changes and documenting the process (Blackman et al. 2009) because features such as change logs, storage of previous versions and approval procedures can be built into the system.

Although changes to the CMP are inevitable over the years, there is a need to maintain the original CMP that outlines the mutually agreed and widely accepted goals of closure, designed to facilitate the intended post-closure land uses and community. These goals also need to be updated from time to time, especially in long mining projects, but the original focus and goals need to be inherited during changes of mine ownership or management. Such maintenance of focus is best achieved by transferring the CMP to the new owners in its entirety. Changes in ownership may be complex and involve transfer of certain assets but not the whole operation and data. This is the case especially for early-phase projects or if the site has been in care and maintenance at the time. A standalone, detachable digital CMP facility that contains the necessary information and data, which can be easily and safely transferred, is clearly needed in these cases.

\section{$5 \quad$ A multitude of stakeholders}

As described above, mine closure involves a multitude of stakeholders that fall into two broad categories: internal stakeholders and external stakeholders, with a different relationship to the closure project. It will be advantageous for the digital management system to cater for working with both stakeholders. Dedicated digital stakeholder engagement systems exist for other project types, such as transport (Steward \& Zegras 2016) and catchment management (Mackay et al. 2015).

A major feature in working with external stakeholders involves collecting and integrating their views on the post-closure land (site) uses. This forms a basis for designing the goals of closure and is crucial for maximising long-term benefits from the project locally. On the other hand, external stakeholders should be kept aware of the progress of the closure process and on whether the aims have been achieved. A mining company likely has other mechanisms in place for interaction with stakeholders, but the content that is prepared for public distribution, such as progress indicators, should be readily accessible in the closure management system. The same is true for internal stakeholders, including the numerous contractors that work at the site-they need to be kept aware of the progress, schedule and goals of closure. The financial department is a special case. They want to know how much funds are needed to complete the planned closure activities each quarter and how much liabilities remain overall. A closure action plan with a schedule and cost estimates for each action can provide this information automatically.

\section{$6 \quad$ Mine closure is an administrative process}

A digital management system for mine closure can help the user in producing official administrative documents required for licences and permits in most jurisdictions. MCPs are typically required for mining licences, EIAs and environmental permits. The final mine closure also needs a plan and usually a permit of its own. In the European Union, a mining waste management plan is also required (European Parliament and 
Council 2006). A system that is based on a detailed, up-to-date internal master plan should have a means to produce these more general public plans with ease by reusing parts of the master plan.

In certain jurisdictions, the authorities have prescribed the format of the administrative CMPs at varying levels of detail (Kabir et al. 2015). While some guidelines only provide the main headings to be used in the document, some jurisdictions have detailed requirements for the plans to be submitted to the authorities. A digital system that contains tailored templates based on the requirements of different jurisdictions can result in marked savings in costs and time in the drafting of these official documents.

\section{$7 \quad$ A costly undertaking}

Mine closure always incurs considerable costs that should be estimated and taken into account in the feasibility stage. According to Byrne (2018), the closure provisions of 57 mining companies (2011-2017) range from AUD 20,000 to AUD 60,000/ha with a median of around AUD 39,000/ha. The cost of waste management alone can vary from less than $1 \%$ to $3-4 \%$ of the total mineral resources extraction costs (Symonds Group 2001) and that of tailings management from EUR 1/t to EUR 10-20/t (Caldwell 2013; Symonds Group 2001).

These costs also form the basis for any financial sureties that authorities may require for the operation. During progressive closure, funds are needed for closure operations carried out over the years. These actions then result in corresponding reductions in the closure-related financial liabilities. The financial departments of the mining company and at the corporate level will want to keep track of all expenditure-the remaining liabilities, the immediate funding needs and the resources already spent. Thus, the digital tool to be developed needs to include features that allow entering cost estimates for various closure actions and keep track of the realised costs (see e.g. Blackman et al. 2019). It should be easy to generate relevant reports on the financial aspects of closure for various uses and to visualise the expenditure. User rights to the system also need to be distributed in a controlled manner to allow relevant actors within the organisation to access this data when necessary, without extra effort from the owners of the mine closure process.

\section{Continuous reduction of risks generates a wealth of data}

Similar to continuously closing those parts of the operation that have reached the end of their service life is the continuous reduction of risks and unknowns in the current paradigm in mine closure. This acknowledges that we will not know all the details from the start, but we can include data collection and test works to the closure plan to reduce these uncertainties. The long lifetime of the operation even allows long-term tests to be carried out to catch the slow processes of mineral alteration. All these actions-monitoring and testinggenerate data and documents. These are primarily stored according to the general data management processes of the company. However, the closure management system should include a mechanism to store these reports and data in a way that links them to context-relevant data and documents linked to correct sections of the CMP, readily available when needed (Mackenzie et al. 2008; Blackman et al. 2009). These links need to remain intact even if the CMP contained in the software is transferred during a change of ownership of the mining project.

\section{Main requirements for a digital closure management tool}

A digital tool dedicated to mine closure management, with the capability to create an MCP, should have the following main characteristics (Figure 1):

- Management of user profiles (administrator, manager, operator, consultant, visitor).

- A master plan generator (where the user can import chapters and sub-chapters from a list, according to its needs).

- A template system to automate information for each chapter and sub-chapter. 
- A guidance system (also called as a knowledge base) with contextual technical information to help the user.

- An action plan allowing the description of all the actions needed for the mine closure and following the logic of 'who, what, where, when' and 'how much'.

- A geographic information system (GIS) tool with a domain approach to facilitate the management of the data and the objects to be rehabilitated.

- A database and repository to store all reports linked to the closure process.

- Indicator screens to monitor the achievement and the closure cost evolution with time.

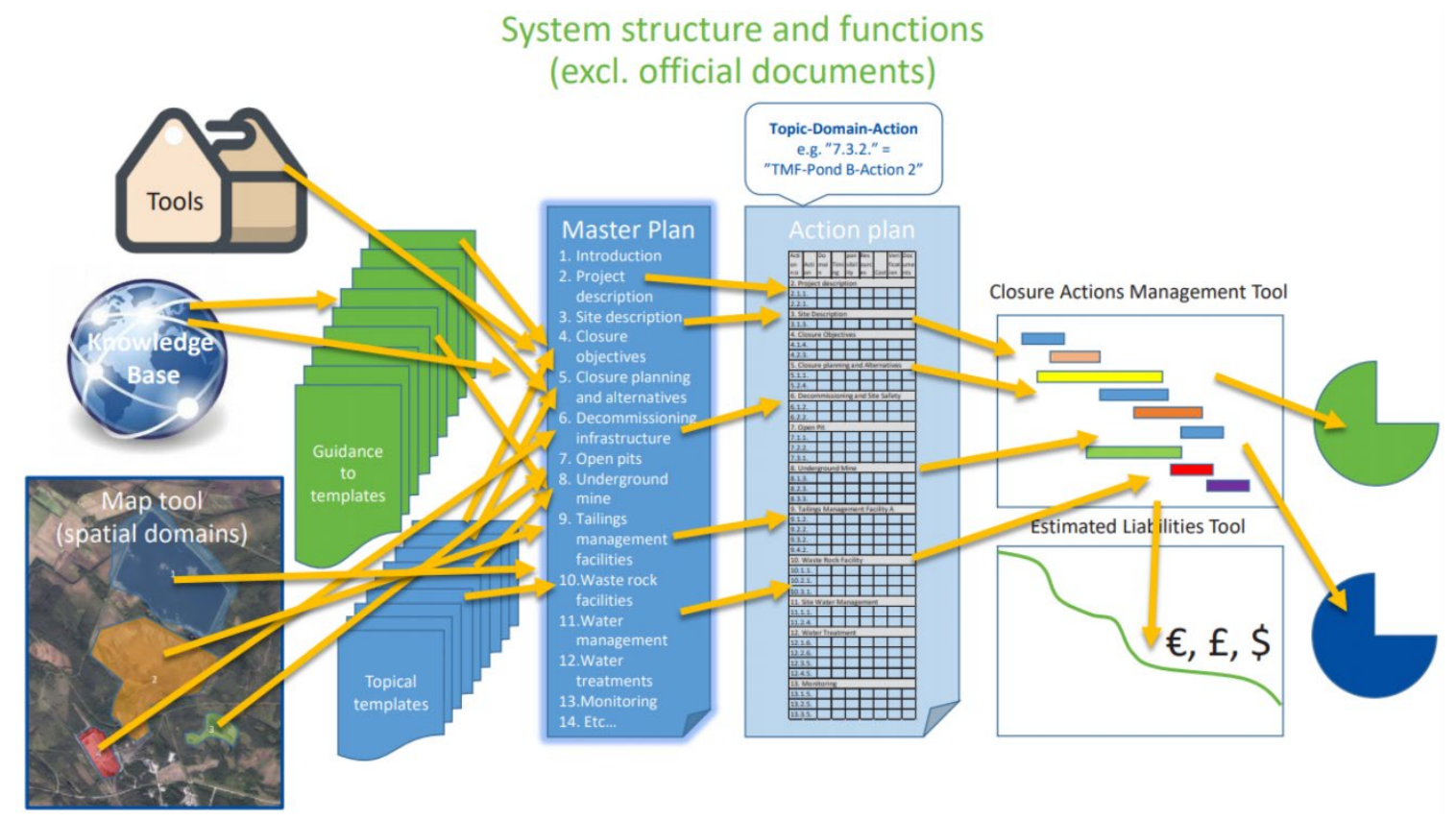

Figure 1 Example of mine closure digital tool structure and functions

\section{Conclusion}

Mine closure is a long, complex process that can greatly benefit from a dedicated digital management tool. Digital tools can help in planning the closure by providing templates and context-sensitive online help for uniform, high-quality MCPs. As the long closure process goes on, a dedicated and independent closure management system - with change logs, version control and documentation-helps in ensuring continuity. This also applies to all closure-related data and documents that should be stored in a way that links them to the correct context. At the same time, a multitude of stakeholders need to be informed of the progress of the closure. These indicators can be produced with little effort using a digital management system. Internally, tracking costs and outstanding liabilities is an important requirement for any closure management system that can greatly reduce the workload when automated. The same is true for any administrative closure documents-the system should assist in producing these from the CMP. All in all, digitalisation of the progressive rehabilitation and closure process for mine sites is likely to provide increased efficiency, improved quality and cost savings once suitable tools are in place for the task.

\section{Acknowledgement}

The Closurematic project is funded by the EIT RM (grant 17032). 


\section{References}

Blackman, KGA, Burne, N, Mitchell, IC, Lacy, HWB \& Mackenzie, S 2009, 'Progressive closure planning at the Magellan Mineproviding some certainty in uncertain times: a case study', in AB Fourie \& M Tibbett (eds), Proceedings of the Fourth International Conference on Mine Closure, Australian Centre for Geomechanics, Perth, pp. 93-100.

Byrne, G 2018, 'Benchmarking closure provisions', in C Drebenstedt, F von Bismarck, AB Fourie \& M Tibbett (eds), Proceedings of the 12th International Conference on Mine Closure, Technical University Bergakademie Freiberg, Freiberg, pp. 91-100.

Caldwell, J 2013, Tailings Management Costs, viewed 9 April 2015, http://ithinkmining.com/2013/08/15/tailings-management-costs Equator Principles Association 2013, The Equator Principles - A Financial Industry Benchmark for Determining, Assessing and Managing Environmental and Social Risk in Projects, viewed 22 July 2019, https://equator-principles.com

European Parliament and Council of the European Union 2006, Directive 2006/21/EC of the European Parliament and of the Council of 15 March 2006 on the management of waste from extractive industries and amending, Directive 2004/35/EC

Global Reporting Initiative 2019, GRI Standards, viewed 22 July 2019, https://www.globalreporting.org/standards/

International Council on Mining and Metals 2019, Integrated Mine Closure: Good Practice Guide, 2nd edn, viewed 22 July 2019 , https://guidance.miningwithprinciples.com/integrated-mine-closure-good-practice-guide/

International Finance Corporation 2012, Environmental and Social Performance Standards, International Finance Corporation, World Bank Group, viewed 22 July 2019, https://www.ifc.org/wps/wcm/connect/Topics_Ext_Content/IFC_External_Corporate_Site /Sustainability-At-IFC/Policies-Standards/Performance-Standards

Joyce, S \& Thomson, I 2000, 'Earning a social licence to operate: Social acceptability and resource development in Latin America'. The Canadian Mining and Metallurgical Bulletin, vol. 93, no. 1037, pp. 49-52.

Kabir, SMZ, Rabbi, F, Chowdhury MB \& Akbar, D 2015, 'A review of mine closure planning and practice in Canada and Australia', World Review of Business Research, vol. 5, no. 3, pp. 140-159.

Mackay, EB, Wilkinson, ME, Macleod, CJA, Beven, K, Percy, BJ, Macklin, MG, Quinn, PF, Stutter, M \& Haygarth, PM 2015, 'Digital catchment observatories: a platform for engagement and knowledge exchange between catchment scientists, policy makers, and local communities', Water Resources Research, vol. 51, iss. 6, pp. 4815-4822.

Mackenzie, S, Mitchell, I \& McGuire, C 2008, 'Progressive rehabilitation and closure planning using GIS-based software at the Mungari Project, Western Australia', Proceedings of the Goldfields Environmental Management Group Workshop 2008, Goldfields Environmental Management Group, Boulder, pp. 71-79.

Moffat, K \& Zhang, A 2014, 'The paths to social licence to operate: an integrative model explaining community acceptance of mining' Resources Policy, vol. 39, pp 61-70, https://doi.org/10.1016/j.resourpol.2013.11.003

Queensland Government 2017, Mined Land Rehabilitation Policy, viewed 2 April 2019, https://environment.des.qld.gov.au/ management/pdf/mined-land-rehabilitation-policy.pdf

Stewart, AF \& Zegras, PC 2016, 'CoAXs: A collaborative accessibility-based stakeholder engagement system for communicating transport impacts', Research in Transportation Economics, vol. 59, pp. 423-433.

Symonds Group 2001, A Study on the Costs of Improving the Management of Mining Waste, report to Directorate-General for the Environment - European Union, Symonds Group Ltd, UK.

World Risk Report 2018, Mining Journal World Risk Report 2018, viewed 22 July 2019, https://www.mining-journal.com/ edition/1000057/mining-journal-world-risk-report-2018-featminehutte-ratings 